\title{
Assessment of the percutaneous endoscopic gastrostomy feeding tube as part of an integrated approach to enteral feeding
}

Claire Wicks, A Gimson, P Vlavianos, M Lombard, M Panos, P Macmathuna, M Tudor, K Andrews, D Westaby

\begin{abstract}
The insertion of percutaneous endoscopic gastrostomy has been well documented. The possible benefits for patient nutrition and nursing practice have, however, not been assessed. We report a study of enteral feeding by percutaneous endoscopic gastrostomy in $\mathbf{3 0}$ patients, the majority with a persistent vegetative state. All patients had previously been fed through a nasogastric tube using manual administration and a dietitian assessed protein calorie intake. Based upon (body mass index (weight/height ${ }^{2}$ ), midarm circumference and triceps skinfold thickness, $20(67 \%)$ were malnourished, with 10 patients having a body mass index $<17$ (severe malnutrition); attributed to high rates of both tube displacement and feed regurgitation. Patients were observed over six to 12 months after percutaneous endoscopic gastrostomy insertion combined with overnight continuous pump feeding. All patients attained a body mass index $>17$, and $17(56 \%)$ of the total number achieved the normal range with no change in protein-calorie intake (pre: 2110 kcal, post: $1880 \mathrm{kcal}$ ). Complications of percutaneous endoscopic gastrostomy in the study group included peritonitis (one), tube site infection (two) and displacement (two); all without serious sequelae. As part of an integrated approach percutaneous endoscopic gastrostomy proved a safe and efficient method of enteral feeding and justifies wider consideration in the United Kingdom.
\end{abstract}

In the United Kingdom the most common method of maintaining nutritional intake in patients unable to swallow is through a nasogastric tube using one of the commercially available fully supplemented enteral feeds. ${ }^{2}$ While preferable to parenteral feeding ${ }^{3+56}$ a number of well documented complications are associated with nasogastric feeding. The most common of these is the accidental displacement with the associated risk of pulmonary aspiration. Other problems include inhibition of oral feeding, tube blockage, nasopharyngeal sepsis and oesophageal erosion. The adverse effects of an indwelling nasogastric tube on the morale of patient and relatives is frequently overlooked. ${ }^{7-12}$ Many of these problems may result in the patient receiving inadequate nutrition. ${ }^{13}$

An alternative method of delivering enteral feeds in these patients is through a gastrostomy tube. Operative gastrostomy remains the most commonly used technique in this country although the procedure is associated with signifcant morbidity and occasional mortality. ${ }^{1+}$

In 1980 Gauderer et al $^{15}$ described a technique for inserting a gastrostomy tube percutaneously using an endoscope approach. The advantages of this procedure in comparison to operative insertion are that it requires only local anaesthesia, takes only 15-20 minutes to insert and can be performed at the patient's bedside if required. Several studies have demonstrated the safety of this technique. ${ }^{16-22}$

The aim of the present study was to assess the nutritional benefits of this means of feed delivery as compared (in a non-randomised fashion) to a nasogastric approach, in 30 patients from a single institution. In addition we have documented the success rate and complications of percutaneous endoscopic gastrostomy insertion in the first 100 cases carried out by this unit.

\section{Methods}

\section{PATIENTS}

Thirty consecutive patients referred for gastrostomy feeding from a single institution, aged between 19 and 76 years were included in the detailed assessment. All had a neurological deficit, of which 19 were attributable to traumatic head injury, four had multiple sclerosis, while four had become anoxic during a surgical procedure, and three had had a cerebrovascular accident.

None of these 30 patients were found to have a contraindication to percutaneous endoscopic gastrostomy insertion (Table I). All patients had been nasogastrically fed using bolus administration during the daytime for periods ranging from two weeks to five years.

Before tube insertion, anthropometric measurements were obtained by a dietitian (CW) and the patients previous feeding regimen was recorded. Height and weight were measured, and expressed as the body mass index, weight $(\mathrm{kg}) / \mathrm{height}\left(\mathrm{m}^{2}\right),\left(\mathrm{W} / \mathrm{H}^{2}\right)$. The resultant figure allowed classification of patients into those with a normal body weight (score 20-24.9) and those with significant undernutrition (score below 20), in which an excess mortality is predicted. ${ }^{23}$

Body composition and nutritional status were estimated by measuring midarm circumference and triceps skinfold thickness using Holtain skinfold callipers and an inelastic tape measure on the non-dominant arm. ${ }^{15-26}$ The results are expressed as percentiles as described by Bishop et al. ${ }^{27}$ The triceps were chosen as the most 
TABLE I Exclusion criteria for percutaneous endoscopic gastrostomy placement

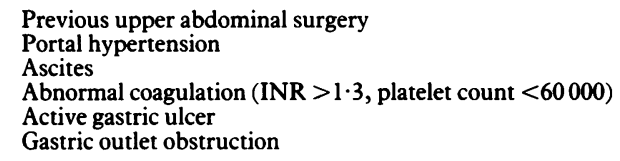

suitable site for measuring the skinfold thickness as it is easily accessible for patients with poor mobility and/or paralysis, it is also least affected by peripheral oedema should it be present.

Subsequent alterations to the feeding regimen during the follow up year were recorded along with the reasons for the change.

The technical aspects of gastrostomy tube insertion have been previously well documented. ${ }^{20}$ In all cases a 9Fr Freka (Fresenius) tube was used. Particular emphasis was placed upon minimising the exposure to risk of complications. Patients were carefully screened for contraindications to percutaneous endoscopic gastrostomy insertion (Table I). The position of the tube was assessed by initial transillumination and finger compression of the abdominal wall. The final distance between the inner and outer flanges of the tube were adjusted to allow 1-2 $\mathrm{cm}$ of expansion which might be predicted with improved nutrition: thus reducing the risk of abdominal wall compression/necrosis.

The gastrostomy feeding tube was not used after insertion for a minimum of six hours. In the absence of pain, pyrexia, tachycardia or hypotension, $500 \mathrm{ml}$ water was given at a rate of $85 \mathrm{ml} /$ hour for the following six hours. Feeding recommenced 12 hours post tube insertion, at a rate of $45 \mathrm{ml}$ per hour for a further 12 hours using the patients previously established nasogastric feeding regimen. If the feed was well tolerated during these first 12 hours then the rate was increased to meet the patients full nutritional requirements.

Anthropometric tests were monitored after one month, three months, six months, and one year.

\section{Results}

The anthropometric measurements showed $67 \%$ (20) of patients to have a body mass index below the 'desirable range' of 20 , at the time of percutaneous endoscopic gastrostomy placement, and of these, $50 \%$ (10) were lower than 17. After one month $13 \%$ (four) of the total were

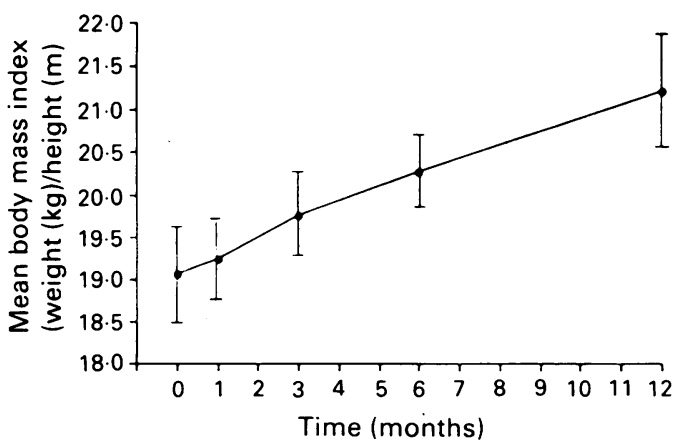

Figure 1: Mean body mass index at 0,1, 3, 6 and 12 months after percutaneous endoscopic gastrostomy tube insertion. below 17 , but still only $30 \%$ (nine) were above 20. At six months $52 \%$ had attained normal weight and only $8 \%$ remained below the score of 17. After a year all patients had achieved weights to bring their body mass index above 17 and $56 \%$ were within or above the normal range. The mean body mass index increased from 19.05 at the start of the study to $21 \cdot 23$ one year later (Fig 1).

Midarm circumference and triceps skinfold thickness measurements were made in 29 patients at the start of the study, 23 at three months and 18 after one year. Weight was monitored for all patients as it is not subject to the large interobserver error that is found with midarm circumference and triceps skinfold thickness measurements. Patients moved to rehabilitation centres in their home towns could still be accurately monitored for weight where they could not for midarm circumference and triceps skinfold thickness.

On baseline assessment of midarm circumference $30 \%$ (nine) of patients, all men, were below the 5 th percentile with only one patient attaining the 50th percentile. By three months, $17 \%$ were still below the 5 th percentile but $22 \%$ were now on the 50th. On the final assessment, after one year, only $11 \%$ remained below the 5 th percentile (Fig 2). Baseline triceps skinfold thickness measurements were compared with standard tables and expressed as a percentile. None of the male patients fell below the 5th percentile, whilst three women did, two of whom increased into the 'desirable range' within the first three months. Before the percutaneous endoscopic gastrostomy tube was inserted 35\% of patients had a triceps skinfold thickness on the 25 th percentile, $24 \%$ on the 50 th and $7 \%$ on the 75th. After three months this had changed to $21 \%$ on the 25 th, $35 \%$ on the 50 th and $7 \%$ on the 75th percentile. By the end of the year, one patient had achieved the 95th percentile while another was on the $90 \mathrm{th}, 35 \%$ were on the 50 th percentile and $35 \%$ were on the 75 th, no patient was below the 10th (Fig 2).

The mean daily energy content of the patients feed before insertion of the gastrostomy tube was $2110 \mathrm{kcal}$. This was adjusted to $1880 \mathrm{kcal}$ during the first six months of the study in response to improvement in nutritional status and to avoid excess weight gain in immobile patients.

Complications were monitored in the 30 study patients, they included peritonitis (one case), tube site infection (two cases) and displacement (two cases) in a total of four patients. This had no significant effect on nutritional status in the long term. The success of percutaneous endoscopic gastrostomy insertion and associated complications were assessed in a larger series comprising the first 100 patients from this unit (Table II). Tube insertion was accomplished in all these 100 consecutive cases although in three patients a second attempt was required. The observed complications are documented for the whole group in Table III. There were no deaths directly related to tube insertion. One patient developed pulmonary aspiration of the feed 30 hours after tube insertion and subsequently died, a complication that could not be directly attributed to the procedure of tube insertion. 

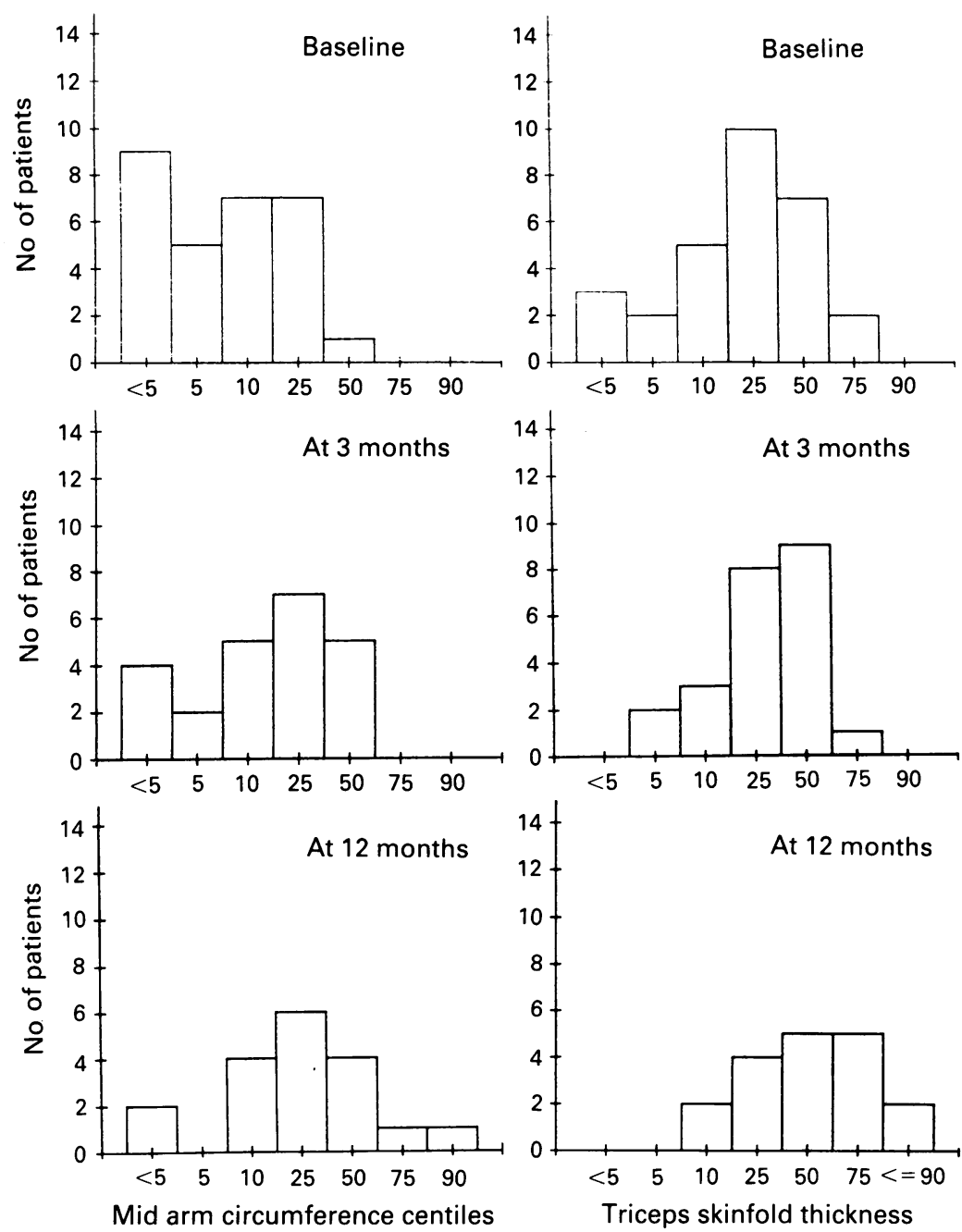

Figure 2: Changes in midarm circumference percentiles and triceps skinfold thickness percentiles at baseline, after three months and at the end of the study.

TABLE II Number and diagnosis of the first 100 patients referred for percutaneous endoscopic gastrostomy placement

\begin{tabular}{ll}
\hline $\begin{array}{l}\text { Patients } \\
(n)\end{array}$ & Diagnosis \\
\hline 66 & $\begin{array}{l}\text { Neurological condition, including 2 with Huntington's } \\
\text { chorea }\end{array}$ \\
32 & $\begin{array}{l}\text { Cystic fibrosis } \\
2\end{array}$ \\
\hline
\end{tabular}

TABLE III Complications of percutaneous endoscopic gastrostomy placement in the first 100 patients

\begin{tabular}{ll}
\hline Complications & $\begin{array}{l}\text { Patients } \\
(n)\end{array}$ \\
\hline Tube site infection & 6 \\
Tube displacement & 4 \\
Peritonitis & 1 \\
\hline
\end{tabular}

\section{Discussion}

This study has highlighted the major problems that may occur with maintaining enteral nutrition, particularly in patients with severe neurological deficit. Despite a carefully supervised regime of nasogastric feeding (with individual assessment of protein and energy intake) $67 \%$ of the 30 patients had evidence of impaired nutrition. By the end of the study period the large majority of patients had gained weight and reduced their caloric intake. In the majority of patients there was a period of months between the head injury and the onset of this study and it is therefore unlikely that the immediate post injury catabolic state is responsible for poor results seen with nasogastric feeding. The most obvious explanation for the initial malnutrition was a high incidence of accidental nasogastric tube displacement or tube occlusion which resulted in periods without enteral nutrition, hence, patients were not in fact receiving their prescribed energy intake. The length of time over which nasogastric tube feeding is discontinued for such reasons is frequently underestimated. ${ }^{13}$

A further important factor to take into consideration with nasogastric feeding is the danger of aspiration. ${ }^{28}$ Many of these patients are sufficiently mobile to partially remove the nasogastric tube and thereby facilitate pulmonary aspiration of the feed. This is particularly relevant at night when it may pass unheeded resulting in major pulmonary complications. This important risk mitigates against continuous overnight nasogastric feeding. The alternative of daytime feeding also has important limitations with respect to decreased patient mobility, particularly important when this interferes with rehabilitation programmes. There are also important cosmetic aspects for both the patients and relatives.

In contrast percutaneous endoscopic gastrostomy tube feeding has a markedly lower risk of pulmonary aspiration and overnight feeding is therefore a feasible option freeing the patient and nursing staff during the daytime to participate more fully in the intensive rehabilitation regimes. ${ }^{29}$

This method of feeding allowed all the patients to gain weight, some to the extent that they became a problem to lift and so had to have their energy intake reduced in order to decrease weight. The results of the body mass index reflect this in that some patients intentionally remained below 20 with the view that they are easier to handle with a lower body weight.

The ease of insertion of percutaneous endoscopic gastrostomy tubes is emphasised by the high success rate accomplished in the larger series of 100 patients. Complications were few in all 100 patients and there was no directly associated morbidity. Strict guidelines for tube management should be produced for nursing staff and carers to prevent tube site infection and displacement, the most frequently encountered complication. This is particularly important during the first two weeks post insertion when the tube tract is still forming and risks of intraperitoneal leakage and sepsis persist. A daily sterile cleaning regimen with change of dressing should suffice. Handling of the tube, particularly close to the point of insertion should be minimised. In agitated patients an abdominal 'tubigrip' dressing was used to protect the site, with the attachment to the feeding pump positioned on the flank, thereby reducing the risk of random arm movements displacing the tube.

This study has confirmed the considerable available evidence supporting both the ease and safety of inserting a gastrostomy tube by the endoscopic approach. For the first time the nutritional benefits of this method of feeding have been documented as compared with the nasogastric approach, albeit in an uncontrolled assessment. In the United States of America this is a currently widely used means of enteral feeding, and from the evidence presented here we would strongly support a much wider application in the United Kingdom. 
The authors would like to acknowledge the assistance of Dr W J Marshall, Dept of Chemical Pathology, King's College Hospital, and also Eileen McKay and Morag Hains, Dietitians at the Royal Hospital and Home, Putney.

1 Bildsten C, Lamid S. Nutritional management of a patient with brain damage and spinal cord injury. Arch Phys Med Rehabil 1983; 64: 382-3.

2 Twyman D, Young AB, Ott L, Norton JA, Bivins BA, et al. High protein enteral feedings: a means of achieving positive nitrogen balance in head injured patients. $\mathcal{F}$ Parenter Entera Nutr 1985; 9: 679-83.

3 Marshall WJ. Nutritional support in hospital practice. Chemistry and Industry 1987; 5: 149-53.

4 Weisner RL, Bacon J, Butterworth CE Jr, et al. Central venous alimentation: A prospective study of the frequency of metabolic abnormalities among medical and surgical patients. F Parenter Enteral Nutr 1982; 6: 421-5.

5 Wagman LD, Newsome HH, Miller KB, Thomas RB, Weir $\mathrm{GC}$, et al. Total parenteral nutrition: acute discontinuation. Ann Surg 1986; 204: 524-9.

6 Bozzetti F. Central venous catheter sepsis. Surg Gynecol Obste 1985; 161: 293-301.

7 Eldar S, Meguid MM. Pneumothorax following attempted nasogastric intubation for nutritional support. $\mathcal{F}$ Parenter Enteral Nutr 1984; 8: 450-2.

8 Grossman TW, Duncavage JA, Dennison B, Kay J, Toohil RJ. Complications associated with a narrow bore nasogastric tube. Ann Otol Rhinol Laryngol 1984; 93: 460-3.

9 Miller KS, Tomlinson JR, Sahn SA. Pleuropulmonary complications of enteral tube feedings. Two reports, review of
the literature, and recommendations. Chest 1985; 88: 230-3.

10 Biggart M, McQuillan PJ, Choudhry AK, Nickalls RW. Dangers of placement of narrow bore nasogastric feeding Dangers of placement of narrow bore nasogast
tubes. Ann R Coll Surg Engl 1987; 69: 119-21.

11 Marcuard SP, Perkins AM. Clogging of feeding tubes. 7 Parenter Enteral Nutr 1988; 12: 403-5.

12 Meer JA. Inadvertent dislodgement of nasoenteral feeding tubes: incidence and prevention. $\mathcal{F}$ Parenter Enteral Nutr 1987; $11: 187-9$.

13 Abernathy GB, Heizer WD, Holcombe BJ, Raasch RH, Schlegel KE, Hak LJ, et al. Efficacy of tube feeding in supplying energy requirements of hospitalized patients. f Parenter Enteral Nutr 1989; 13: 387-91.
14 Shellito PC, Malt RA. Tube gastrostomy. Techniques and complications. Ann Surg 1985; 201: 180-5.

15 Gauderer MWL, Ponsky JL, Izant RJ Jr. Gastrostomy without laparotomy: A percutaneous endoscopic technique. without laparotomy: A percutane

16 Ponsky JL, Gauderer MW, Stellato TA. Percutaneous endoscopic gastrostomy. Review of 150 cases. Arch Surg 1983;

17 Strodel WE, Lemmer J, Eckhauser F, Botham M, Dent T. Early experience with endoscopic percutaneous gastrostomy. Arch Surg 1983; 118: 449-53.

18 Larson DE, Fleming CR, Ott BJ, Schroeder KW. Percutaneous endoscopic gastrostomy. Simplified access for enteral nutrition. Mayo Clin Proc 1983; 58: 103-7.

19 Thatcher BS, Ferguson DR, Paradis K. Percutaneous endoscopic gastrostomy: a preferred method of feeding tube gastrostomy. Am f Gastroenterol 1984; 79: 748-50.

20 Russell TR, Brotman M, Norris F. Percutaneous gastrostomy. A new simplified and cost-effective technique. Am $\mathcal{F}$ Surg 1984; 148: 132-7.

21 Ponsky JL, Gauderer MW, Stellato TA, Aszodi A. Percutaneous approaches to enteral alimentation. Am $\mathcal{F}$ Surg 1985 ; 149: $102-5$.

22 Kirby DF, Craig RM, Tsang TK, Plotnick BH. Percutaneous endoscopic gastrostomies: a prospective evaluation and review of the literature. $\mathcal{F}$ Parenter Enteral Nutr 1986; 10: 155-9.

23 Garrow JS. Treat obesity seriously. Edinburgh: Churchill Livingstone, 1981 .

24 Schulz LO. Obese, overweight, desirable, ideal; where to draw the line in 1986? F Am Diet Assoc 1986; 86: 1702-4.

25 Thomas B. Manual of dietetic practice. Oxford: Blackwell Scientific, 1988.

26 Bishop CW, Ritchey SJ. Estimation of the mid-upper arm circumference measurement error. $\mathcal{f}$ Am Diet Assoc 1987; 87: 469-73.

27 Bishop CW, Bowen PE, Ritchey SJ. Norms for nutritional assessment of American adults by upper arm anthropometry. Am f Clin Nutr 1981; 34: 2530-9.

28 Metheny NA, Eisenberg P, Spies-M. Aspiration pneumonia in patients fed through nasoenteral tubes. Heart Lung 1986; 15: 256-61.

29 Kocan MJ, Hickisch SM. A comparison of continuous and intermittent enteral nutrition in NICU patients. $\mathcal{J}$ Neurosc Nurs 1986; 18: 333-7. 